\title{
QUEEN'S
UNIVERSITY
BELFAST
}

\section{Towards a Mobile Assistive Technology for Monitoring and Assessing Cognitive Fatigue in Individuals with Acquired Brain Injury}

Price, E., Moore, G., Galway, L., \& Linden, M. (2015). Towards a Mobile Assistive Technology for Monitoring and Assessing Cognitive Fatigue in Individuals with Acquired Brain Injury. In 2015 IEEE International Conference on Computer and Information Technology; Ubiquitous Computing and Communications; Dependable, Autonomic and Secure Computing; Pervasive Intelligence and Computing (CIT/IUCC/DASC/PICOM) [32623] Institute of Electrical and Electronics Engineers Inc.. https://doi.org/10.1109/CIT/IUCC/DASC/PICOM.2015.222

Published in:

2015 IEEE International Conference on Computer and Information Technology; Ubiquitous Computing and Communications; Dependable, Autonomic and Secure Computing; Pervasive Intelligence and Computing (CIT/IUCC/DASC/PICOM)

\section{Document Version:}

Peer reviewed version

Queen's University Belfast - Research Portal:

Link to publication record in Queen's University Belfast Research Portal

\begin{abstract}
Publisher rights
(C) 2015 IEEE. Personal use of this material is permitted. Permission from IEEE must be obtained for all other uses, in any current or future media, including reprinting/republishing this material for advertising or promotional purposes, creating new collective works, for resale or redistribution to servers or lists, or reuse of any copyrighted component of this work in other works.
\end{abstract}

\section{General rights}

Copyright for the publications made accessible via the Queen's University Belfast Research Portal is retained by the author(s) and / or other copyright owners and it is a condition of accessing these publications that users recognise and abide by the legal requirements associated with these rights.

Take down policy

The Research Portal is Queen's institutional repository that provides access to Queen's research output. Every effort has been made to ensure that content in the Research Portal does not infringe any person's rights, or applicable UK laws. If you discover content in the Research Portal that you believe breaches copyright or violates any law, please contact openaccess@qub.ac.uk. 


\section{Towards a Mobile Assistive Technology for Monitoring and Assessing Cognitive Fatigue in Individuals with Acquired Brain Injury}

\author{
Edward Price \\ Computer Science Research Institute \\ Ulster University \\ Jordanstown, United Kingdom \\ price-e@email.ulster.ac.uk \\ George Moore \\ Computer Science Research Institute \\ Ulster University \\ Jordanstown, United Kingdom \\ g.moore@ulster.ac.uk
}

\author{
Computer Science Research Institute \\ Ulster University \\ Jordanstown, United Kingdom \\ l.galway@ulster.ac.uk
}

\author{
Mark Linden
}

School of Nursing and Midwifery

Queens University Belfast

Belfast, United Kingdom

m.linden@qub.ac.uk

\section{Leo Galway}

\begin{abstract}
Those living with an acquired brain injury often have issues with fatigue due to factors resulting from the injury. Cognitive impairments such as lack of memory, concentration and planning have a great impact on an individual's ability to carry out general everyday tasks, which subsequently has the effect of inducing cognitive fatigue. Moreover, there is difficulty in assessing cognitive fatigue, as there are no real biological markers that can be measured. Rather, it is a very subjective effect that can only be diagnosed by the individual. Consequently, the traditional way of assessing cognitive fatigue is to use a self-assessment questionnaire that is able to determine contributing factors. State of the art methods to evaluate cognitive fatigue employ cognitive tests in order to analyse performance on predefined tasks. However, one primary issue with such tests is that they are typically carried out in a clinical environment, therefore do not have the ability to be utilized in situ within everyday life. This paper presents a smartphone application for the evaluation of fatigue, which can be used daily to track cognitive performance in order to assess the influence of fatigue.
\end{abstract}

Keywords - cognitive fatigue; fatigue; reaction time; psychomotor vigilance task; spatial span; smartphone; mobile;

\section{INTRODUCTION}

Fatigue can be defined as "the awareness of a decreased capacity for physical and/or mental activity due to an imbalance in the availability, utilisation, and/or restoration of [physiological or psychological] resources needed to perform activity” [1]. Cognitive fatigue is a common symptom that may occur after an Acquired Brain Injury (ABI) and can have a very detrimental effect on a person's ability to carry out activities of daily living. There is an inherit difficulty when self-diagnosing fatigue due to its subjective nature. Measuring cognitive fatigue, it is very problematic due to the absence of biological markers and no standardised test for it, resulting in a lack of technology-based approaches within this area [3]. Consequently, episodes of fatigue can potentially go unnoticed or unrecognised. Fatigue in terms of ABI can be either a direct effect of the brain injury or a side effect from some other cognitive of physical deficit. Fatigue is often pinpointed as the most serious and debilitating symptom of $\mathrm{ABI}$ yet more research is being done into fatigue within other domains (e.g. cancer, multiple sclerosis, stroke) [3].

The aim of the research discussed in this paper is to investigate how cognitive fatigue can be accurately assessed in situ through the use of mobile assistive technology. Assessment most frequently takes place in a clinical environment, which doesn't allow for assessment in everyday life. Tests such as the Psychomotor Vigilance Task and Spatial Span can be adapted onto a mobile device, and in turn could be used to more accurately assess fatigue. Validity of this approach would be confirmed through its testing alongside an already proven self assessment method modified for mobile use. Self-assessment of cognitive fatigue takes the form of a simple, easy to comprehend questionnaire.

The remainder of this paper goes on to look at the related work in the area to give a solid understanding of current approaches and determine gaps in specific areas of research. Once this has been analysed, then the proposed system design will be outlined showing how relevant research will be used to inform the design of an application. Finally, a conclusion of the research will be presented along with future work that will be undertaken.

\section{RELATED WORK}

There have been a number of specific self-assessment questionnaires designed to target cognitive ability and its relation to fatigue, including the Visual Analogue Scale for Fatigue [4], Fatigue Severity Scale [5] and the Mental Fatigue Scale [6]. All of these scales use a visual analogue representation of targeted questions in order to aid a participant in self-evaluation. Moreover, the validity of such scales has been evaluated and shown to be effective in their assessment capabilities [7].

As self-assessment is a key approach to monitoring fatigue, it has great potential to be adapted and deployed onto 
mobile platforms. Within the research literature, Swendeman et al. [8] carried out a study into the validity of self-reporting accessed via a smartphone. They evaluated behavioural and emotional self-reports daily over a 6-week period. Daily completion rates of surveys were reported to be $50 \%$, with $70 \%$ of participants completing three follow up surveys after the 6-week period. Adherence to the daily assessment was observed to be low, which was attributed to errors in data that subsequently had to be excluded from the evaluation results. One suggested remedy to this issue was the use of prior training with the technology, as it is often the case that braininjured individuals find technology difficult to use due to their impairments [9]. It may also show how self assessment on a mobile deice is monotonous to a participant, highlighting the need for a more engaging approach.

In addition to approaches employing selfassessment, test methods have also been traditionally utilised to determine relative cognitive ability. Specific cognitive tests from the Wechsler Adult Intelligence Scale (WAIS) have been shown to be effective when used to evaluate fatigue [10]. The Cambridge Neuropsychological Test Automated Battery (CANTAB) uses the same approach of utilising simple cognitive tests to specifically detect the current mental capacity and cognitive functioning of an individual. The computerised tests allow for a detailed level of accuracy in testing for a more comprehensive view of cognitive ability that cannot be found in paper based tests.

Wilkinson [13] was the first to determine that an auditory vigilance task is sensitive to fatigue due to sleep loss. Dinges and Powell [14] then modified this, and developed a 10-minute version of the Psychomotor Vigilance Task. This task was again found to be sensitive to fatigue due to sleep deprivation [15]. Subsequently, vigilance tasks were considered more sensitive to the components of sleep than subjective measures of sleepiness and fatigue because people frequently underestimate the cognitive impact of sleep deprivation [11].

Van Dongen [11] defined three computerised methods for assessing fatigue after chronic sleep restriction: (1). a mental arithmetic test to assess cognitive throughput; (2) a sustained reaction time test (Psychomotor Vigilance Test); (3) a digit-symbol substitution task to assess memory. While many technology-based approaches exist that are capable of assessing fatigue within a clinical environment, to date there have been a lack of effort at developing such approaches for mobile platforms in order to facilitate their use outside of a clinical environment.

Johansson [18] compared the ability of a mental fatigue questionnaire with cognitive tests to determine if there is a direct correlation in their ability to subjectively and objectively measure fatigue. The neuropsychological tests employed included Digit Symbol Coding, Digit Span, Spatial Span [19] and Trail Making Tests [20]. These were used to measure processing speed attention, working memory, verbal fluency and reading speed. It was concluded that subjective mental fatigue, following brain injury, mainly correlates with objectively measured information processing speed [18].

The Spatial Span used by Johansson, taken from the Wechsler Adult Intelligence Scale (WAIS), measures the same cognitive attention and working memory ability as the digit-symbol substitution task defined by Van Dongen as a metric to measure fatigue [11]. The only difference being that it is a simpler task and so is easier for individuals with acquired brain injury to actively engage in. Furthermore, its simplicity aids for development and deployment on a mobile platform for fatigue evaluation.

The PVT was originally designed for a static computer based evaluation, but is one of the few tests that has been modified for use on mobile platforms for more natural conditions and usefulness for on the go assessment. Work by Kay [16] and Gartenberg [17] looked at how effective short mobile tests would be and what, if any, usability issues that arise. Concluding that mobile versions where just as effective as desktop based assessments showing the adaptability of cognitive tasks. Assessments only focused on measuring vigilance as an evaluation of alertness and would have benefited from additional measurements such as working memory and throughput.

\section{SYSTEM DESIGN}

The system described here adapts the Mental Fatigue Scale to help validate the results of our approach. This self-assessment scale is the first that has been adapted to assess fatigue regardless of an individual's neurological illness rather than being aimed at a specific condition. Its validity has been assessed alongside a series of neuropsychological tests [21]. Consequently, it has been chosen for adoption in the smartphone-based approach discussed herein, together with three different cognitive tests: (1) the Spatial Span test from WAIS; (2) the PVT; (3) Serial Addition Subtraction Task. Correspondingly, the cognitive tests selected require sufficient cognition to evaluate multiple different areas of affect, including memory, attention, speed of processing and cognitive throughput. The subsequent design of a smartphone-based application that incorporates all three neuropsychological tests, along with the mental fatigue scale self-assessment questionnaire, will facilitate in situ data collection of cognitive fatigue related symptoms. Furthermore, mobile devices permit situational evaluation that gives the added ability of including real world contextual data, such as time of day, within the assessment.

The system we have designed invites the user to participate in a daily series of self-assessment and cognitive tasks, designed to last no longer than 10 minutes. Instructional information will be presented prior to each task to ensure participants can correctly use and understand each test. Figure 1 presents a high-level system diagram illustrating data storage internally and externally in a remote database. Data is stored in the mobile application once a test is complete and is then sent to a secure server. This is to allow immediate access to the data by relevant medical practitioners in order to provide any further assessment and feedback. 
The initial step of the application will be to check if the cognitive fatigue test has been taken in the current day. If it hasn't then the user will be prompted to participate in the test. Prompt response rate will be collected alongside the testing data so that application user experience can be analysed. This data is collected in the background when the test is taking place and at the end all data is aggregated and saved to internal and external databases for evaluation. The following sections outline each step within the application that the user will take. It also outlines the additional process that the application will carry out in the background such as data management, collection and storage.

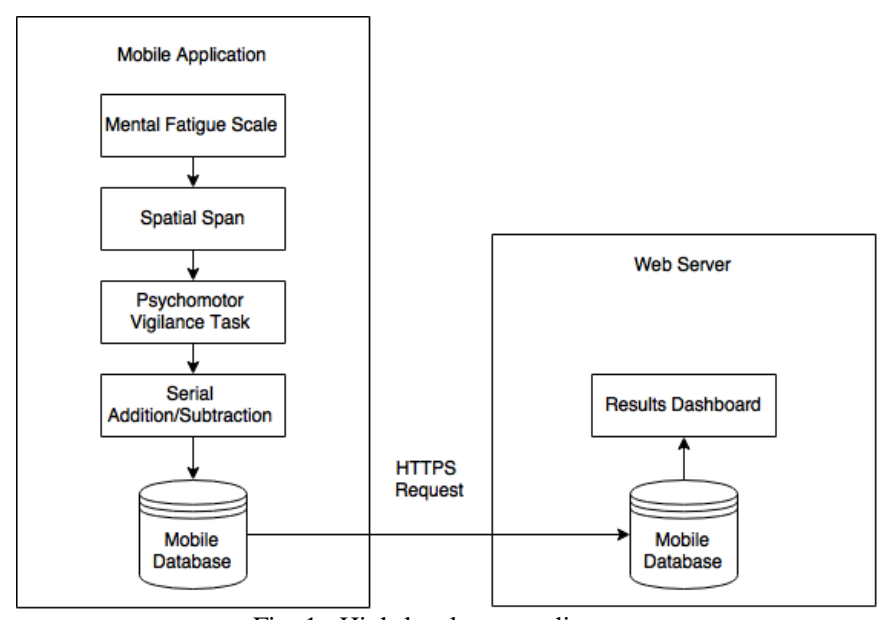

Fig. 1. High-level system diagram

\section{A. Self assessment (Mental Fatigue Scale)}

Self-assessment is an already well-established method of evaluating fatigue [7] and so initial assessment from the application will take place via the 15-question Mental Fatigue Scale adapted for mobile usage. This initial self-assessment stage will allow for a baseline measure of fatigue that subsequent testing data can be analysed against.

\section{B. Spatial Span}

The next step within the application will test cognitive attention and working memory through a Spatial Span test. The Spatial Span is one of the more simpler tasks to asses attention and working memory due to it not have any additional numbering or object sequences to memorise. This easier engagement may potentially lead to a higher rate of participation due to reduced frustration [22].

\section{Psychomotor Vigilance Task}

As previously noted, the PVT is a proven method to evaluate fatigue [23]. Reaction times are collected in milliseconds; analysis of these times have been shown to correlate with wakefulness and fatigue [14].

\section{Serial Addition/Subtraction Task}

The serial addition subtraction task was included in the assessment battery to measure cognitive throughput [12]. Previous use of this task has shown its effectiveness in assessing the characteristics associated with fatigue [11]. It is a time-based task requiring the completion of as many random mental arithmetic questions within a certain period of time. The average number of correct responses can then be used to assess cognitive throughput performance.

\section{E. Participation Prompting}

Task prompting in the area of ABI has been widely used as an effective compensatory method for memory impairments

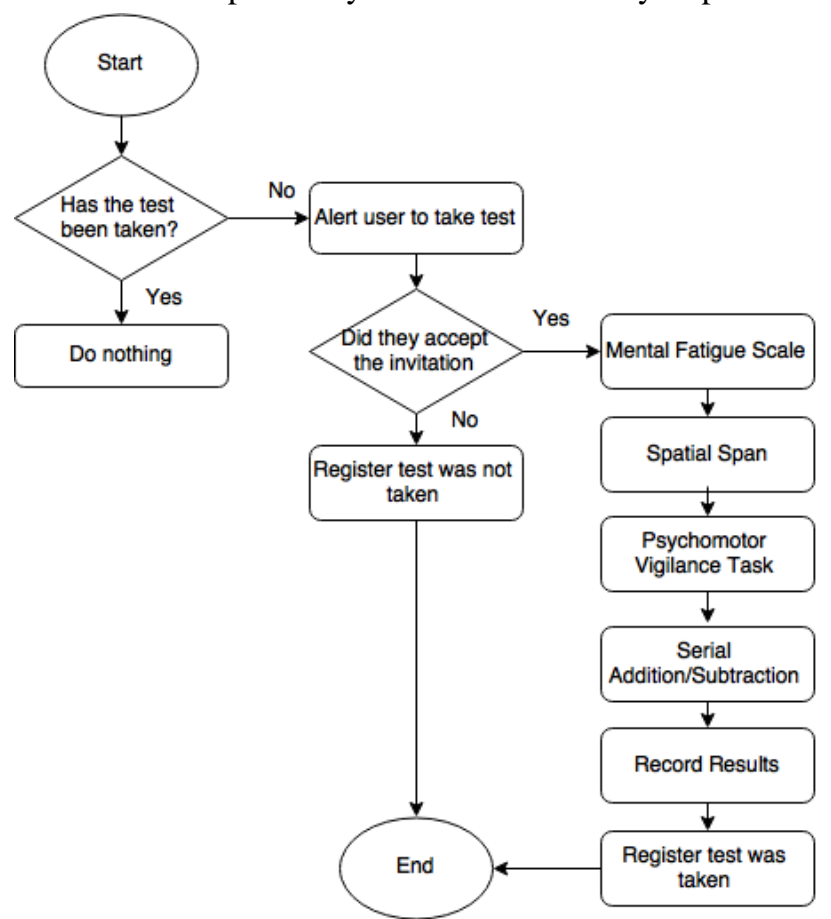

Fig. 2. System flowchart diagram showing participant use of the application

[24][25]. To help increase participation in the daily testing, notifications will be periodically issued to the smartphone in order to prompt the user to carry out the test. If the test has already been taken on the specific day then no prompt will be shown. Prompting also takes away the pressure of having to remember each day making the test more engaging to use.

\section{F. Data Collection and Storage}

In order to collate, store and process the large amount of data that will potentially be acquired, all testing results will be initially stored on a user's device. It will subsequently be transmitted to a central external database hosted on a web server for ease of access, after every time the test is completed. Another benefit of initially storing test data on device is that it pre-empts any potential connection errors to the database, which could result in a loss of information. The centralised server will utilize MySQL to store the data in a structured table format that can then be accessed for further analysis. Both the data and data types that will be acquired using the smartphone during tests are given in Table 1 . The stored data can then be displayed on a webpage dashboard for a medical professional to analyse and evaluate.

Figure 2 shows each step in the application from start to end including system decision and resulting data recorded from multiple scenarios. Data is not recorded until the full test has been completed, this is to prevent incomplete data records.

\section{USE CASE}

The case of a 26-year old woman with an acquired brain injury is presented. She reports that her daily exercise is reduced and that she is having trouble participating in previously simple everyday tasks. There is a loss of ability to stay motivated and often feels tired even after no physical or mental exertion. She does not feel physically tired or over exerted and so is concerned over her lack of motivation for 
TABLE I

DATA COLLECTED FORM MOBILE FATIGUE ASSESSMENT APPLICATION

\begin{tabular}{|c|c|c|c|}
\hline Test & $\begin{array}{l}\text { FACTORS } \\
\text { MEASURED }\end{array}$ & Data Collected & Type of Data \\
\hline \multirow[t]{2}{*}{$\begin{array}{l}\text { Mental } \\
\text { Fatigue Scale }\end{array}$} & $\begin{array}{l}\text { Overall } \\
\text { fatigue } \\
\text { assessment }\end{array}$ & $\begin{array}{l}\text { Date and time test } \\
\text { was started }\end{array}$ & Date/Time \\
\hline & & $\begin{array}{l}\text { Questionnaire } \\
\text { Results }\end{array}$ & Numerical array \\
\hline \multirow[t]{5}{*}{ Spatial Span } & $\begin{array}{l}\text { Cognitive } \\
\text { attention and } \\
\text { working } \\
\text { memory }\end{array}$ & $\begin{array}{l}\text { Amount of } \\
\text { sequences complete }\end{array}$ & Numerical \\
\hline & & $\begin{array}{l}\text { Highest sequence } \\
\text { reached }\end{array}$ & Numerical \\
\hline & & $\begin{array}{l}\text { Number of correct } \\
\text { sequences }\end{array}$ & Numerical \\
\hline & & $\begin{array}{l}\text { Number of wrong } \\
\text { sequences }\end{array}$ & Numerical \\
\hline & & $\begin{array}{l}\text { Time to complete } \\
\text { each full sequence }\end{array}$ & Numerical Array \\
\hline \multirow{3}{*}{$\begin{array}{l}\text { Psychomotor } \\
\text { Vigilance } \\
\text { Task }\end{array}$} & $\begin{array}{l}\text { Alertness and } \\
\text { reaction time }\end{array}$ & Reaction times & Numerical Array \\
\hline & & $\begin{array}{l}\text { Amount of reactions } \\
\text { that were before } \\
\text { prompt (wrong) }\end{array}$ & Numerical \\
\hline & & $\begin{array}{l}\text { Amount of reactions } \\
\text { that were after } \\
\text { prompt (right) }\end{array}$ & Numerical \\
\hline \multirow[t]{5}{*}{$\begin{array}{l}\text { Serial } \\
\text { addition/ } \\
\text { subtraction }\end{array}$} & $\begin{array}{l}\text { Cognitive } \\
\text { throughput }\end{array}$ & $\begin{array}{l}\text { Number of correct } \\
\text { answers }\end{array}$ & Numerical \\
\hline & & $\begin{array}{l}\text { Number of wrong } \\
\text { answers }\end{array}$ & Numerical \\
\hline & & $\begin{array}{l}\text { Questions that was } \\
\text { asked }\end{array}$ & Numerical Array \\
\hline & & Correct answer & Numerical Array \\
\hline & & Users answer & Numerical Array \\
\hline
\end{tabular}

daily tasks. Cognitive fatigue has been pinpointed as a probable explanation but accurate assessment within everyday life is needed so that the correct diagnosis can be made.

Supporting this scenario in traditional terms would involve daily or weekly check ups with a medical practitioner in order for assessment to be carried out, or else a log of problematic scenarios may be kept and reviewed at a later date for evaluation. The system we have designed would allow for the evaluation of cognitive fatigue outside of a medical environment on a daily basis. Mobile reminders prevent the participant in forgetting to take part in the daily task so that more informative data can be collected. The selfassessment Mental Fatigue Scale will be presented one question at a time to make it visually easier to process on a mobile device. Design of the questions as well as the entire application will follow Apples IOS Human Interface Guidelines [26] to ensure clarity in UI elements and interactivity in keeping with the operating system. All navigation, typography, icons and terminology will be in keeping with IOS guidelines to make sure that the application is intuitive to use. The Spatial Span will be presented for 90 seconds with the participant trying to remember and complete as many sequences as they can in the allowed time. Each correct sequence increases the difficulty by adding another item to the following sequence. The participant will then carry out the Psychomotor Vigilance Task 15 times and try and react as quickly as possible to a changing stimuli. Pre emptied reactions by the participant will be counted and deducted from the total. Finally the Serial Addition/Subtraction Task will be presented for 90 seconds allowing the user to complete as many simple mental arithmetic questions as quickly as possible. The questions will only include the numbers 1-9 so that they aren't taxing for an individual that may already be suffering from cognitive fatigue. Once finished all data will be saved locally on a participants device as well as sent to a remote server where it can be analysed by a medical professional in order to properly monitor the patient and adjust the proscribed tasks accordingly.

\section{CONCLUSION \& FUTURE WORK}

This paper presents a novel design for mobile cognitive fatigue assessment and its relationship with subjective and objective measures of fatigue in patients with acquired brain injury. Based on previous research, the following hypotheses have been formulated: (1) ABI participants suffering from differing levels of cognitive fatigue would exhibit a reduced level of performance in Spatial Span, PVT and mental arithmetic tasks; (2) a correlation exists between testing performance and subjective fatigue reported on the Mental Fatigue Scale; (3) accurate cognitive fatigue assessment can be carried out on a mobile application for use in everyday life.

An initial two-week study will be conducted with healthy participants to validate the effectiveness of the approach and its accuracy. Results from the study will validate if the application is fit for purpose in individuals with acquired brain injuries. Also it will permit refinement of the application if necessary based on general participant feedback.

Future work will aim to firstly investigate if a contextual model can be developed that takes into account fatigue assessment data alongside situational data in order to facilitate a more detailed assessment of conditions. Furthermore, when a contextual model is developed it will be integrated into the smartphone application. This level of context will allow for deeper understanding in the analysis of the test results obtained and maybe even permit prediction of the onset of fatigue, which will facilitate tailored assessment and feedback, along with personalised and more effective prompting.

\section{REFERENCES}

[1] L. S. Aaronson, C. S. Teel, V. Cassmeyer, G. B. Neuberger, L. Pallikkathayil, and A. W. Janet Pierce, Allan N. Press, Phoebe D. Williams, “Defining and Measuring Fatigue,” J. Nurs. Scholarsh., vol. 31, no. 1, pp. 45-50, 1999.

[2] a. Belmont, N. Agar, C. Hugeron, B. Gallais, and P. Azouvi, "Fatigue and traumatic brain injury,” Ann. Réadaptation Médecine Phys., vol. 49, no. 6, pp. 370-374, Jul. 2006.

[3] C. Ziino and J. Ponsford, "Measurement and prediction of subjective fatigue following traumatic brain injury,” J. Int. ..., pp. 416-425, 2005.

[4] A. Shahid, K. Wilkinson, S. Marcu, and C. Shapiro, "Visual Analogue Scale to Evaluate Fatigue Severity (VAS-F),” in STOP, THAT and One Hundred Other Sleep Scales SE - 100, A. Shahid, K. Wilkinson, S. Marcu, and C. M. Shapiro, Eds. Springer New York, 2012, pp. 399 402.

[5] K. LB, L. NG, M.-N. J, and S. AD, “The fatigue severity scale: Application to patients with multiple sclerosis and systemic lupus erythematosus,” Arch. Neurol., vol. 46, no. 10.

[6] B. Johansson, A. Starmark, P. Berglund, M. Rödholm, and L. Rönnbäck, “A self-assessment questionnaire for mental fatigue and related symptoms after neurological disorders and injuries,” Dec. 2009.

[7] K. a Lee, G. Hicks, and G. Nino-Murcia, "Validity and reliability of a scale to assess fatigue.,” Psychiatry Res., vol. 36, no. 3, pp. 291-298, 1991.

[8] D. Swendeman, W. S. Comulada, N. Ramanathan, M. Lazar, and D. Estrin, "Reliability and Validity of Daily Self-Monitoring by Smartphone Application for Health-Related Quality-of-Life, 
Antiretroviral Adherence, Substance Use, and Sexual Behaviors Among People Living with HIV,” AIDS Behav., vol. 19, no. 2, pp. 330 340, 2014.

[9] A.-L. L. Engström, J. Lexell, and M. L. Lund, "Difficulties in using everyday technology after acquired brain injury: a qualitative analysis.,” Scand. J. Occup. Ther., vol. 17, no. 3, pp. 233-243, 2010.

[10] B. Johansson and L. Rönnbäck, "Mental Fatigue; A Common Long Term Consequence After a Brain Injury,” 2009.

[11] H. Van Dongen, G. Maislin, J. M. Mullington, and D. F. Dinges, “The cumulative cost of additional wakefulness: dose-response effects on neurobehavioral functions and sleep physiology from chronic sleep restriction and total," Sleep, vol. 26, no. 2, pp. 117-126, 2003.

[12] D. R. Thorne, S. G. Genser, H. C. Sing, and F. W. Hegge, “The Walter Reed performance assessment battery.," Neurobehav. Toxicol. Teratol., 1985.

[13] R. T. Wilkinson, "Methods for research on sleep deprivation and sleep function.,” Int. Psychiatry Clin., vol. 7, no. 2, pp. 369-381, 1969.

[14] D. F. Dinges and J. W. Powell, "Microcomputer analyses of performance on a portable, simple visual RT task during sustained operations,” Behav. Res. Methods, Instruments, Comput., vol. 17, no. 6, pp. 652-655, 1985.

[15] S. Loh, N. Lamond, J. Dorrian, G. Roach, and D. Dawson, "The validity of psychomotor vigilance tasks of less than 10-minute duration,” Behav. Res. Methods, Instruments, Comput., vol. 36, no. 2, pp. 339-346, May 2004.

[16] M. Kay and K. Rector, "PVT-touch: adapting a reaction time test for touchscreen devices,” Pervasive ..., pp. 248-251, 2013.

[17] D. Gartenberg and R. McGarry, "Development of a Neuroergonomic Application to Evaluate Arousal,” Adv. ..., pp. 6378-6387, 2012.

[18] B. Johansson, P. Berglund, and L. Rönnbäck, "Mental fatigue and impaired information processing after mild and moderate traumatic brain injury.,” Brain Inj., vol. 23, no. 13-14, pp. 1027-40, Dec. 2009.
[19] D. Wechsler, "Wechsler adult intelligence scale-Fourth Edition (WAIS-IV)," San Antonio, TX NCS Pearson, 2008.

[20] R. M. Reitan and D. Wolfson, The Halstead-Reitan neuropsychological test battery: Theory and clinical interpretation, vol. 4. Reitan Neuropsychology, 1985.

[21] B. Johansson, H. Bjuhr, and L. Rönnbäck, "Evaluation of an Advanced Mindfulness Program Following a Mindfulness-Based Stress Reduction Program for Participants Suffering from Mental Fatigue After Acquired Brain Injury,” Mindfulness (N. Y)., 2013.

[22] A. Lindén, J. Lexell, and M. L. Lund, "Perceived difficulties using everyday technology after acquired brain injury: influence on activity and participation.,” Scand. J. Occup. Ther., vol. 17, no. 4, pp. 267-75, Dec. 2010.

[23] S. P. a Drummond, A. Bischoff-Grethe, D. F. Dinges, L. Ayalon, S. C. Mednick, and M. J. Meloy, "The neural basis of the psychomotor vigilance task.,” Sleep, vol. 28, no. 9, pp. 1059-1068, 2005.

[24] Y.-J. Chang, S.-F. Chen, and L.-D. Chou, "A feasibility study of enhancing independent task performance for people with cognitive impairments through use of a handheld location-based prompting system.," IEEE Trans. Inf. Technol. Biomed., vol. 16, no. 6, pp. 115763, Nov. 2012

[25] B. Das, B. L. Thomas, A. M. Seelye, D. J. Cook, L. B. Holder, and M. Schmitter-Edgecombe, "Context-aware prompting from your smart phone,” 2012 IEEE Consum. Commun. Netw. Conf., pp. 56-57, Jan. 2012.

[26]

https://developer.apple.com/library/ios/documentation/UserExperienc e/Conceptual/MobileHIG/ Accessed July 2015 